\title{
Evaluation of lymph node numbers for adequate staging of Stage II and III colon cancer
}

Chandrakumar Shanmugam ${ }^{1}$, Robert B Hines ${ }^{2}$, Nirag C Jhala ${ }^{3}$, Venkat R Katkoori', Bin Zhang ${ }^{4}$, James A Posey Jr ${ }^{5,7}$, Harvey L Bumpers ${ }^{6}$, William E Grizzle ${ }^{1,7}$, Isam E Eltoum ${ }^{1,7}$, Gene P Siegal ${ }^{1,7}$ and Upender Manne ${ }^{1,7^{*}}$

\begin{abstract}
Background: Although evaluation of at least 12 lymph nodes (LNs) is recommended as the minimum number of nodes required for accurate staging of colon cancer patients, there is disagreement on what constitutes an adequate identification of such LNs.

Methods: To evaluate the minimum number of LNs for adequate staging of Stage II and III colon cancer, 490 patients were categorized into groups based on 1-6, 7-11, 12-19, and $\geq 20$ LNs collected.

Results: For patients with Stage II or III disease, examination of 12 LNs was not significantly associated with recurrence or mortality. For Stage II (HR $=0.33 ; 95 \% \mathrm{Cl}, 0.12-0.91)$, but not for Stage III patients $(\mathrm{HR}=1.59 ; 95 \% \mathrm{Cl}$, 0.54-4.64), examination of $\geq 20 \mathrm{LNs}$ was associated with a reduced risk of recurrence within 2 years. However, examination of $\geq 20 \mathrm{LNs}$ had a 55\% (Stage II, HR =0.45; 95\% Cl, 0.23-0.87) and a 31\% (Stage III, HR = 0.69; 95\% Cl, 0.38-1.26) decreased risk of mortality, respectively. For each six additional LNs examined from Stage III patients, there was a $19 \%$ increased probability of finding a positive LN (parameter estimate $=0.18510, p<0.0001$ ). For Stage II and III colon cancers, there was improved survival and a decreased risk of recurrence with an increased number of LNs examined, regardless of the cutoff-points. Examination of $\geq 7$ or $\geq 12$ LNs had similar outcomes, but there were significant outcome benefits at the $\geq 20$ cutoff-point only for Stage II patients. For Stage III patients, examination of 6 additional LNs detected one additional positive LN.
\end{abstract}

Conclusions: Thus, the 12 LN cut-off point cannot be supported as requisite in determining adequate staging of colon cancer based on current data. However, a minimum of $6 \mathrm{LNs}$ should be examined for adequate staging of Stage II and III colon cancer patients.

Keywords: Colon cancer, Clinical outcomes, Lymph nodes, Stage II, Stage III

\section{Background}

In 2010, an estimated 51,370 deaths from colorectal cancer (CRC) are expected to have occurred, accounting for $9 \%$ of all cancer deaths in the USA [1]. For CRC patients, the stage of the disease predicts long-term survival and is weighed in designing treatments [2]. The acquisition of a single positive lymph node (LN) identifies Stage III patients, and the prognosis worsens as the number of involved LNs increases [3]. These patients are characterized by a high recurrence rate but may be benefitted by adjuvant chemotherapy [4-6]. Currently,

\footnotetext{
* Correspondence: manne@uab.edu

'Departments of Pathology, University of Alabama at Birmingham, Birmingham, AL 35294, USA

Full list of author information is available at the end of the article
}

due to conflicting results from clinical trials and population-based studies, the role of adjuvant chemotherapy for Stage II patients remains controversial [6]. Some investigators, however, recommend chemotherapy for all high-risk Stage II CRC patients, including those with inferior LN recoveries and with peritoneal involvement, extramural vascular invasion, tumor perforation and/or tumor obstruction $[3,7]$.

$\mathrm{LN}$ involvement is the key factor that determines the stage and prognosis for CRCs [8]. Nevertheless, LN positivity alone does not identify all patients with a poor prognosis, as 20 to $40 \%$ of patients with Stage II (LNnegative) disease die of their cancers $[9,10]$. In population-based studies, the percentages of CRCs in Stages II and III are approximately $40 \%$ and $30 \%$, with 5 -year,

\section{() Biomed Central}


cancer-specific survival rates ranging between $50-80 \%$ and $30-60 \%$, respectively $[11,12]$. The proportion of Stage III tumors may, however, be higher than reported because of missing $\mathrm{LN}$ metastases due to inadequate examination and resulting under-staging [13]. The suggested minimum number of LNs to be examined to stage these patients has ranged between 6 and 20 [11,14-18]. The World Congress of Gastroenterology proposed examination of a minimum of $12 \mathrm{LNs}$ for classification of tumors as Stage II [19]. In the USA, the American Joint Committee on Cancer (AJCC), the American Society of Clinical Oncology (ASCO) and the College of American Pathologists (CAP), American College of Surgeons (ACoS), Commission on Cancer (CoC), and the National Comprehensive Cancer Network $(\mathrm{NCCN})$ have also recommended examination of at least 12 LNs to assign Stage II disease [8,20,21].

Several institutional and population-based studies showed a survival benefit associated with increasing numbers of LNs examined from Stage II and Stage III CRC patients [22-25]. The origin of the database (Surveillance Epidemiology and End Results, SEER, versus NCCN) also influenced the findings of LN examination on patient prognosis [17]. In one investigation, increased numbers of LNs examined was associated with improvements in overall survival and relapse-free survival for Stage II but not in Stage III patients [26]. Goldstein [27] reported that the predictive probability of finding positive LNs increased with increasing numbers of LNs examined. In contrast, Bui et al [22] and Wong et al [15] found no substantial increase in LN positivity with increased numbers of examined LNs.

The recommendation by AJCC, ASCO, ACoS-CoC, CAP, and NCCN, that examination of $\geq 12 \mathrm{LNs}$ is sufficient to stage a patient with CRC would seem to end the debate yet anecdotal evidence suggests these recommendations may not be followed. To determine how many LNs should be examined from Stage II and III patients with colon cancer, we evaluated a consecutive retrospective cohort and assessed cancer-specific mortality and recurrence. We also attempted to derive a minimum number of LNs needed to stage patients appropriately and thus to minimize under-staging.

\section{Methods \\ Patients}

This investigation was approved by the Institutional Review Board and Bioethics Committee of the University of Alabama at Birmingham (UAB). This cross-sectional study was comprised of Stage II and III cancer patients who underwent surgery for adenocarcinoma of the colon at UAB Hospital from 1981-2002. Follow-up ended in December, 2010. The initial study population consisted of 566 patients. To minimize the influence of familial/hereditary CRCs, patients $<45$ years old $(\mathrm{n}=$ 23) were excluded, as were those with missing LN information ( $\mathrm{n}=31)$. Patients who died within one week of surgery $(\mathrm{n}=12)$ and those who received neoadjuvant chemotherapy $(\mathrm{n}=8)$ were also excluded. Two were removed due to missing tumor grade information. The final study population was 490 . In this study, only about 22\% (50 of 230) of patients with Stage III disease had received adjuvant chemotherapy for various clinical reasons, and the treatment information was accounted for in the survival analyses.

\section{Study design}

Three pathologists (CS, NCJ, and WEG) extracted the pathologic features from pathology reports and confirmed by reviewing hematoxylin and eosin stained sections. CRCs were classified by the tumor-nodemetastasis (TNM) method and staged according to the AJCC system [21]. Tumor grade was recorded as well differentiated, moderately differentiated, poorly differentiated, or unknown; no tumors were graded as undifferentiated. Well and moderately differentiated tumors were designated as "low" grade, and poorly differentiated tumors as "high" grade [8]. Tumor size was also obtained, and a dichotomous variable was created $(\geq 5$ and $<5 \mathrm{~cm}$ ).

Demographic, clinical, and patient information regarding age at the time of surgery, gender, race, surgery date, and adjuvant chemotherapy was obtained from medical records. Age was categorized as $<65$ and $\geq 65$ years. Subjects were classified as non-Hispanic African American, or non-Hispanic Caucasian American, based on self-identification. Patients who had adjuvant treatment were categorized as "yes" if they received any 5fluorouracil-based chemotherapy.

\section{Statistical analysis}

A nominal categorical variable, including the current recommendation of examining $12 \mathrm{LNs}$, was created for the number of LNs examined based on a quartile distribution. Patients were categorized by the number of LNs examined at surgery into four groups: 1-6, 7-11, 12-19, and $\geq 20$. Survival time was calculated from the date of surgery until either death, the termination date of the study, or the last date of contact for patients who were still alive at the end of the study. The primary events of interest were colon cancer-specific death and recurrence of disease. All reported $P$ values were two-sided; statistical significance was defined as $P<0.05$. All analyses were performed with SAS statistical software, version 9.2.

The chi-square $\left(\chi^{2}\right)$ statistics for categorical variables and the t-test for continuous variables were used to assess differences with respect to vital status, demographics along with tumor-related and clinical variables 
according to tumor stage. Log-rank tests and Kaplan Meier survival curves [28] were used to compare Stage III pN1 patients with Stage III pN2 patients for colon cancer-specific or disease-specific survival (DSS). The type I error rate for each test was controlled at $<0.05$. For Stage II and III patients, hazard ratios (HRs) for the bivariate association between the numbers of LNs obtained and other covariates with death due to colon cancers were assessed separately. From the bivariate analysis, all variables that were associated with cancerspecific mortality and risk of recurrence at $P<0.20$ were entered into the initial multivariable model containing the number of LNs collected as a categorical variable. To obtain the final model for cancer-related mortality, the least significant variable was removed in a step-wise manner. The association between LN examination and recurrence (at 2 and 5 years) or cancer-specific survival was obtained with the overall survival as well as 5-year cancer-specific survival and risk of recurrence. The final multivariable models for survival and recurrence were used separately to obtain HRs for the association between the numbers of LNs examined and cancer-specific survival and risk of recurrence. These multivariable, stage-specific models were adjusted for age, race, gender, treatment, and tumor location, size, and grade to assess the cancer-specific survival or risk of recurrence. For LN-positive patients, the association between the number of LNs examined (continuous) and the number of positive LNs found was assessed. For stage III (LN-positive) patients, linear regression was used to estimate the association between the number of LNs examined (continuous) as a predictor for the number of positive LNs. The linear regression equation to obtain parameter estimation was: $Y=\beta_{0}+\beta_{1} X_{1}+\beta_{2} X_{2}$ $+E\left(Y=\right.$ number of positive lymph nodes, $\beta_{1}=$ the number of lymph nodes examined, and $\beta_{2}=$ covariate, $X_{1}=$ the value of number of lymph nodes examined, $X_{2}=$ is the value of a covariate, and $E=$ error term). For Stage III patients, the probability of a tumor being classified as $\mathrm{pN} 2$ ( $\geq 4$ positive LNs) was obtained for the four categories of LNs.

\section{Results}

\section{The characteristics of the study population and their} cancers

The median age of the study population was 68 (45 to 99 years). As shown in Table 1, Stage III patients were younger $(<65: \mathrm{n}=98,42.6 \% ; P=0.02)$ than Stage II patients $(\mathrm{n}=85,32.7 \%)$. There were more patients with larger tumors in Stage II ( $\geq 5 \mathrm{~cm}: \mathrm{n}=144,55.4 \% ; P=$ $0.04)$ than in Stage III $(\mathrm{n}=106,46.1 \%)$. In accordance with current treatment recommendations, more Stage III patients received adjuvant chemotherapy $(\mathrm{n}=50$, 21.7\%; $P<0.0001)$.
There was a significant difference between Stage II and Stage III according to the vital status $(P<0.0001)$. As compared to Stage II patients $(\mathrm{n}=77,29.6 \%)$, more Stage III patients died due to colon cancer $(\mathrm{n}=123$, $53.5 \%)$. There were more recurrences within two years among Stage III patients compared to Stage II patients $(P=0.048)$. However, there was no stage difference according to the number of LNs extracted relative to gender, race, or tumor grade.

\section{The association between the number of LNs collected and colon cancer recurrence}

Compared to patients with $<12$ LNs identified, collection of $\geq 12$ LNs was not significantly associated with recurrence at 2 or 5 years, as determined by multivariate analyses of Stage II and III colon cancers (Table 2). For Stage II patients, the higher categories of LNs obtained were associated with a decreased risk of recurrence, although only the $\geq 20$ category approached significance, with a $67 \%$ decreased risk of recurrence within 2 years $(\mathrm{HR}=0.33$; 95\% CI, 0.12-0.91). The stage-wise association between LNs harvested and 5-year recurrence, however, was not statistically significant (Table 2). For Stage III patients, there was no relationship between increasing numbers of LNs examined with cancer recurrence (Table 2).

The rates of recurrence decreased with increases in the number of LNs removed for both Stage II $(R=$ -0.692, $\mathrm{p}=0.0004)$ (Figure 1A) and III $(R=-0.774, \mathrm{p}<$ 0.0001) (Figure 1B) patients; however, for Stage II and III colon cancer patients, there was no statistically significant difference in the rates of recurrence after the collection of 6 - 19 LNs (Table 2).

\section{The association between the number of LNs obtained and disease-specific survival}

As noted for recurrence at 2 years, multivariate analyses showed that collection of 12 LNs as the cutoff was not significantly associated with disease-specific survival (DSS) for Stage II ( $\mathrm{HR}=0.61 ; 95 \% \mathrm{CI}, 0.37-1.00)$ or Stage III $(\mathrm{HR}=0.97 ; 95 \% \mathrm{CI}, 0.64-1.46)$ (Table 3) patients. Multivariate analyses according to the categorical variables, showed, however, that, compared to the category of 1-6 $\mathrm{LN}$ retrieved, the three higher categories (7-11, 12-19, $\geq$ 20 ) exhibited an improved 5 -year and overall DSS. The $\geq$ 20 category had significantly better survival than those with $<6$ LNs in Stage II (5 years-HR $=0.42$; 95\% CI, 0.20 0.90; overall- $\mathrm{HR}=0.45 ; 95 \% \mathrm{CI}, 0.23-0.87$ ) but not for Stage III ( 5 years-HR $=0.74 ; 95 \%$ CI, $0.39-1.40$; overall$\mathrm{HR}=0.69 ; 95 \% \mathrm{CI}, 0.38-1.26)$ (Table 3$)$.

\section{The association between the number of LNs retrieved} with LN positivity in Stage III colon cancer

The number of positive LNs examined was obtained for Stage III patients. As determined by linear 
Table 1 Characteristics of the study population $(N=490)$

\begin{tabular}{|c|c|c|c|c|c|}
\hline \multirow[b]{2}{*}{ Variable } & \multicolumn{3}{|c|}{ Stagell $(n=260,53.1 \%)$} & \multicolumn{2}{|c|}{ Stage III ( $n=230,46.9 \%)$} \\
\hline & $n$ & (\%) & $n$ & $(\%)$ & $P$ value \\
\hline Age (years) & & & & & 0.024 \\
\hline$<65$ & 85 & 32.7 & 98 & 42.6 & \\
\hline$\geq 65$ & 175 & 67.3 & 132 & 57.4 & \\
\hline Sex & & & & & 0.959 \\
\hline Male & 134 & 51.5 & 118 & 51.3 & \\
\hline Female & 126 & 48.5 & 112 & 48.7 & \\
\hline Race & & & & & 0.202 \\
\hline Caucasian Americans & 165 & 63.5 & 133 & 57.8 & \\
\hline African Americans & 95 & 36.5 & 97 & 42.2 & \\
\hline Tumor grade & & & & & 0.380 \\
\hline Low & 216 & 83.1 & 184 & 80.0 & \\
\hline High & 44 & 16.9 & 46 & 20.0 & \\
\hline Tumor location & & & & & 0.521 \\
\hline Distal & 100 & 38.5 & 95 & 41.3 & \\
\hline Proximal & 160 & 61.5 & 135 & 58.7 & \\
\hline Tumor size (cm) & & & & & 0.040 \\
\hline$<5$ & 116 & 44.6 & 124 & 53.9 & \\
\hline$\geq 5$ & 144 & 55.4 & 106 & 46.1 & \\
\hline Adjuvant chemotherapy & & & & & $<0.0001$ \\
\hline No & 237 & 91.2 & 180 & 78.3 & \\
\hline Yes & 23 & 8.8 & 50 & 21.7 & \\
\hline Status & & & & & $<0.0001$ \\
\hline Alive & 89 & 34.2 & 59 & 25.6 & \\
\hline Death due to colon cancer & 77 & 29.6 & 123 & 53.5 & \\
\hline Death due to other causes & 94 & 36.2 & 48 & 20.9 & \\
\hline Recurrence (years) & & & & & 0.048 \\
\hline No & 209 & 80.4 & 163 & 70.9 & \\
\hline$\leq 2$ & 35 & 13.5 & 47 & 20.4 & \\
\hline$>2$ & 16 & 6.1 & 20 & 8.7 & \\
\hline Number of LNs harvested & & & & & 0.615 \\
\hline $1-6$ & 55 & 21.2 & 38 & 16.5 & \\
\hline $7-11$ & 63 & 24.2 & 57 & 24.8 & \\
\hline $12-19$ & 75 & 28.8 & 73 & 31.7 & \\
\hline$\geq 20$ & 67 & 25.8 & 62 & 27.0 & \\
\hline
\end{tabular}

regression analysis, each additional LN collected resulted in a $19 \%$ increased probability of collecting a positive LN (parameter estimate $=0.1851, \mathrm{p}<0.0001$ ). Therefore, collection of six additional LNs resulted in identification of one additional positive LN (1/ $0.1851=5.4$ ).
The association between the number of LNs obtained with the probability of identifying $\mathrm{pN}_{2}$ tumors in stage III colon cancer

Logistic regression was utilized to obtain the predictive probability (PP) of obtaining $\geq 4$ positive $\mathrm{LNs}\left(\mathrm{pN}_{2}\right.$ designation) according to the number of LNs obtained, 
Table 2 Multivariate analyses of numbers of LNs obtained and recurrence of colon cancer at 2 and 5 years

\begin{tabular}{|c|c|c|}
\hline \multirow[b]{2}{*}{ LNs extracted } & \multicolumn{2}{|c|}{ Adjusted $^{a}$ HRs (95\% C.I.) } \\
\hline & Stage II & Stage III \\
\hline \multicolumn{3}{|c|}{ Recurrence in 2 years } \\
\hline \multicolumn{3}{|c|}{ Current guideline } \\
\hline$<12$ & ref & ref \\
\hline$\geq 12$ & $0.62(0.32,1.22)$ & $1.27(0.67,2.40)$ \\
\hline \multicolumn{3}{|l|}{ Quartiles } \\
\hline $1-6$ & ref & ref \\
\hline $7-11$ & $0.72(0.29,1.79)$ & $1.49(0.52,4.26)$ \\
\hline $12-19$ & $0.63(0.26,1.52)$ & $1.54(0.55,4.34)$ \\
\hline$\geq 20$ & $0.33(0.12,0.91)$ & $1.59(0.54,4.64)$ \\
\hline
\end{tabular}

$\underline{\text { Recurrence in } 5 \text { years }}$

Current guideline

$\begin{array}{ccc}<12 & \text { ref } & \text { ref } \\ \geq 12 & 0.67(0.37,1.24) & 1.16(0.67,1.99)\end{array}$

Quartiles

$1-6$

$7-11$

$12-19$

$\geq 20$

$\begin{array}{cc}\text { ref } & \text { ref } \\ 0.64(0.27,1.51) & 1.24(0.53,2.91) \\ 0.62(0.26,1.52) & 1.23(0.53,2.84) \\ 0.47(0.20,1.11) & 1.44(0.61,3.42)\end{array}$

$\mathrm{HR}$, hazard ratio; $\mathrm{Cl}$, confidence interval.

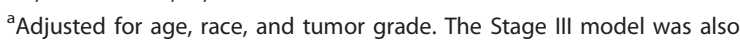
adjusted for chemotherapy status and the number of positive LNs.

after adjustment for other confounders. Patients with 16 LNs collected had an $18 \%(\mathrm{PP}=0.184)$ chance of having a $\mathrm{pN}_{2}$ tumor. Patients with 7-11 and 12-19 nodes obtained had probabilities of $37 \%(\mathrm{PP}=0.370)$ and $38 \%$ $(\mathrm{PP}=0.382)$, respectively. Patients with $\geq 20 \mathrm{LNs}$ extracted had a $43 \%$ chance $(\mathrm{PP}=0.433)$ of having a $\mathrm{pN}_{2}$ tumor (data not shown). Analysis of Stage III CRCs based on the status of nodal involvement $\left(\mathrm{pN}_{1}\right.$ versus $\mathrm{pN}_{2}$ ) demonstrated no significant difference in the rate of recurrence within $2(\mathrm{HR}=2.43,95 \% \mathrm{CI}, 1.37-4.32)$ or 5 years $(\mathrm{HR}=2.06,95 \% \mathrm{CI}, 1.26-3.39)$ (data not shown); however, patients with $\mathrm{pN}_{2}$ colon cancers had a lower survival than $\mathrm{pN}_{1}$ patients $(\log$-rank $\mathrm{p}=0.012$ ) (Figure 2).

\section{Discussion}

For both Stage II and III colon cancer patients, increased numbers of LNs retrieved were associated with reduced risk of recurrence and improved cancerspecific survival. Identification of $\geq 20 \mathrm{LNs}$ correlated significantly with reduced risk of recurrence and

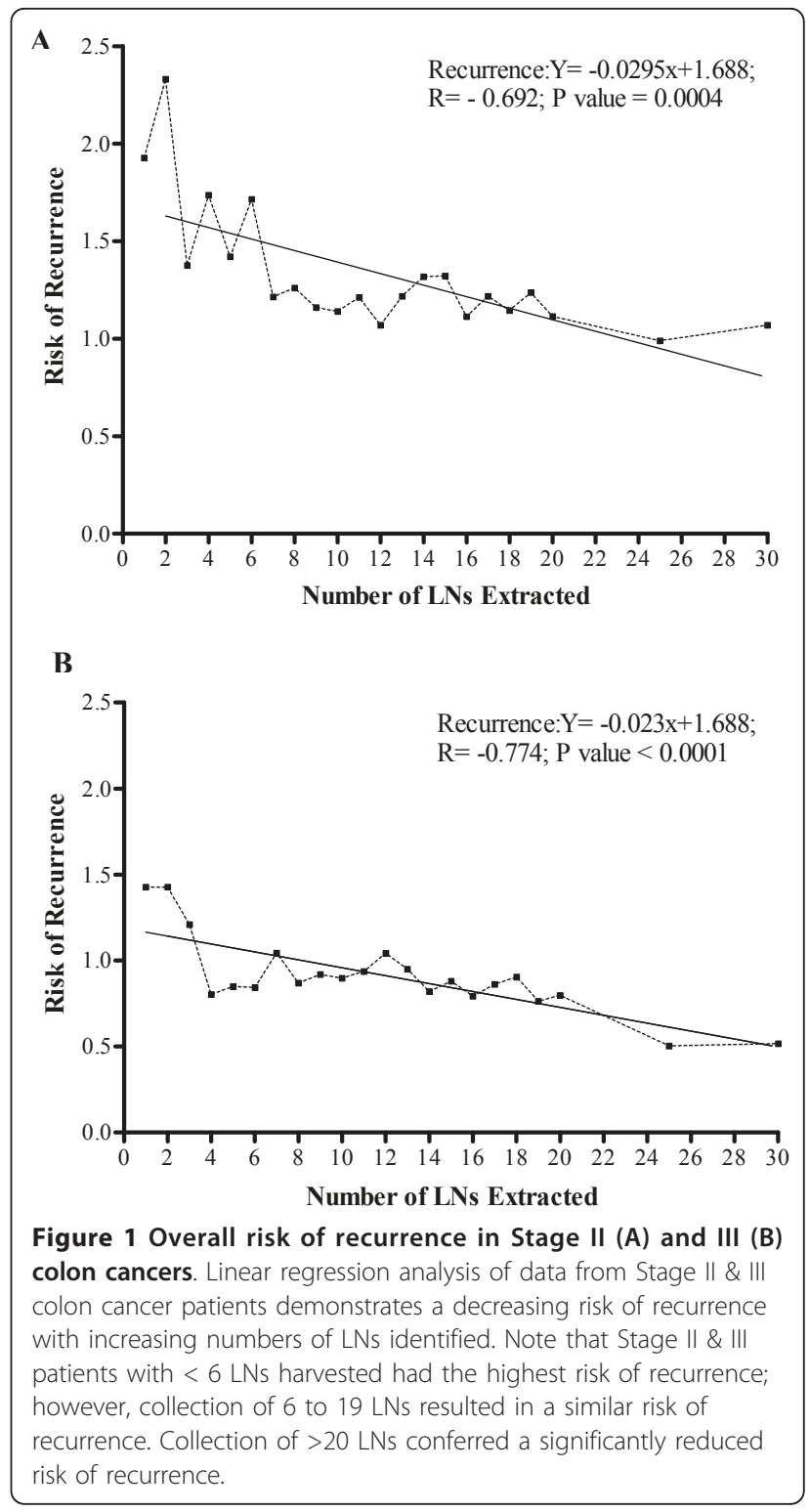

mortality of Stage II but not Stage III patients. For Stage III patients, collection of six additional LNs resulted in identification of one additional positive $\mathrm{LN}$, and the probability of finding patients with $\mathrm{pN}_{2}$ nodal stage increased with increasing numbers of LNs examined.

LN involvement determines the pathologic stage and forms the basis for selection of patients for adjuvant therapy [8]. Although Stage II disease, which has a relatively good prognosis, is characterized by the absence of LN involvement, about one third of these patients experience recurrences, due either to missed micrometastases or to aberrant drainage of LNs beyond the field of resection, leading to under-staging $[3,9,12]$. Furthermore, for Stage III patients, inadequate LN recognition is associated with a poorer prognosis 
Table 3 Bivariate and multivariate associations of number of lymph nodes harvested with 5-year and overall colon cancer-specific survival

\begin{tabular}{|c|c|c|c|c|}
\hline \multirow[b]{2}{*}{ LNs extracted } & \multicolumn{2}{|c|}{ Un-adjusted HRs (95\% C.I.) } & \multicolumn{2}{|c|}{ Adjusted $^{a}$ HRs (95\% C.I.) } \\
\hline & Stage II & Stage III & Stage II & Stage III \\
\hline \multicolumn{5}{|l|}{5 Years DSS } \\
\hline \multicolumn{5}{|c|}{ Current guideline } \\
\hline$<12$ & ref & ref & ref & ref \\
\hline$\geq 12$ & $0.65(0.40,1.07)$ & $1.13(0.77,1.64)$ & $0.61(0.37,1.00)$ & $0.97(0.64,1.46)$ \\
\hline \multicolumn{5}{|l|}{ Quartiles } \\
\hline $1-6$ & ref & ref & ref & ref \\
\hline $7-11$ & $0.93(0.60,1.43)$ & $1.64(0.91,2.94)$ & $0.85(0.43,1.67)$ & $0.87(0.41,1.85)$ \\
\hline $12-19$ & $0.89(0.58,1.34)$ & $0.97(0.55,1.71)$ & $0.68(0.35,1.32)$ & $0.97(0.55,1.70)$ \\
\hline$\geq 20$ & $0.54(0.35,0.83)$ & $1.02(0.57,1.82)$ & $0.42(0.20,0.90)$ & $0.74(0.39,1.40)$ \\
\hline
\end{tabular}

Overall DSS

Current guideline

$<12$

$\geq 12$

Quartiles

$1-6$

$7-11$

$12-19$

$\geq 20$ ref

$0.69(0.44,1.07)$

ref

$0.69(0.37,1.28)$

$0.68(0.38,1.24)$

$0.45(0.23,0.87)$ ref

$1.09(0.76,1.56)$

ref

$0.84(0.48,1.48)$

$1.01(0.60,1.70)$

$0.94(0.55,1.61)$ ref

$0.65(0.42,1.02)$

ref

$0.75(0.40,1.40)$

$0.67(0.37,1.22)$

$0.45(0.23,0.87)$ ref

$0.95(0.64,1.40)$

ref

$0.83(0.47,1.47)$

$0.94(0.56,1.59)$

$0.69(0.38,1.26)$

DSS, disease-specific survival; $\mathrm{HR}$, hazard ratio; $\mathrm{Cl}$, confidence interval.

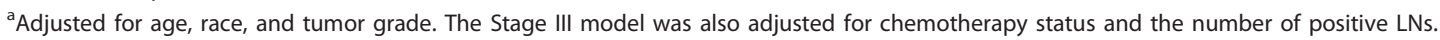

$[15,22]$, and increased LN collection has a favorable effect on prognosis [29-31]. Thus, diligent searches for LNs are needed for accurate assessment of nodal status and for correct assignment of stage.

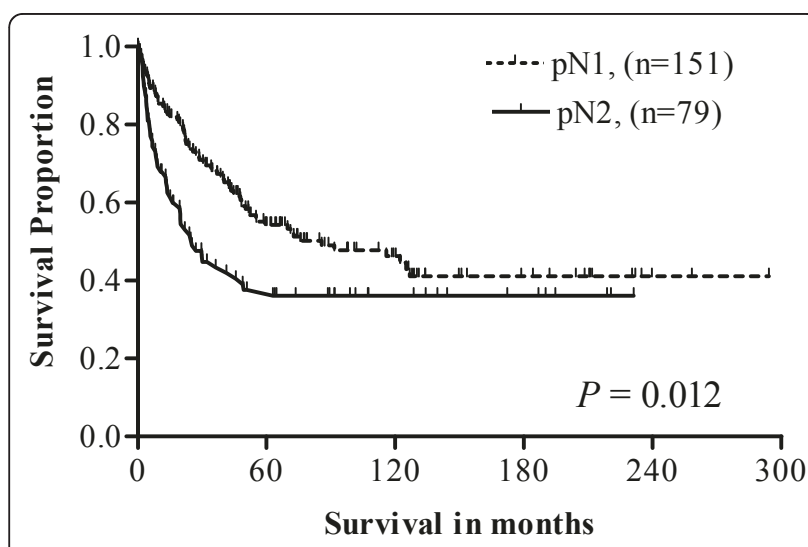

Figure 2 Survival in pN1 vs. pN2 Stage III colon cancers. KaplanMeier survival curves demonstrating significant difference in diseasespecific survival between Stage III patient groups of pN1 and pN2.
The AJCC, ASCO, CAP, ACoS-CoC, and NCCN have recommended that a minimum of $12 \mathrm{LNs}$ be examined in order to rule out metastases via the lymphatic system to nodal tissues $[8,20,21]$. This recommendation, however, is not widely practiced. Only $58 \%$ of those in the SEER database had $\geq 12$ LNs harvested [17], and the NCCN database review documented a $60 \%$ failure rate in achieving resection of $12 \mathrm{LNs}$ among various USA hospitals [18]. Various minimum numbers of LNs harvested (range: 6 to 40) from colon resections, have been suggested for adequate staging of colon cancer patients [15,22,26,32].

An increased LN examination confers a survival benefit, especially for stage II disease [14,27,32-34]. In the current investigation, however, examination of 12 LNs showed no significant survival benefit. By disease stage, there was a $55 \%$ and $31 \%$ reduced risk of cancer-specific mortality for Stage II and III patients, respectively, for those with $\geq 20$ LNs examined. The 5-year survival of Stage II cases was $54.9 \%$, whereas the survival of those who had $\geq 9$ LNs examined after surgery was $79.9 \%$ 
[35]. The 5-year survival of Stage II patients who had $\leq$ 8 LNs examined was similar to that for Stage III patients (51.8\%). Sixteen of 17 studies of Stage II and 4 of 6 studies of Stage III showed improved patient survival with increased number of LNs examined [16]. In contrast, for Stage III patients, the number of LNs examined did not serve as a prognosticator [36]. The demonstration of increased mortality associated with the examination of $\leq$ 6 LNs, compared to $>6$, especially in Stage II patients, is in concordance with other reports $[16,24,27]$.

With tumor recurrence as the outcome for Stage II patients, all higher categories of LN collections showed a decreased risk, but only the $\geq 20$ category approached significance, with a $67 \%$ decreased risk of recurrence within 2 years after surgery. In contrast, for Stage III patients, there was no relationship between increasing numbers of LNs examined with colon cancer recurrence. A low risk of recurrence for patients with $\geq 14$ LNs examined compared to smaller numbers was reported earlier [32]. There was a significant difference in recurrence with the number of LNs examined. Further, for $\mathrm{pN}_{1}$ and $\mathrm{pN}_{2}$ patients, disease-free survival improved as more LNs were removed, but there was no such association for node-negative patients. The impact of $\mathrm{LN}$ ratio (ratio of tumor-infiltrated nodes to total number of harvested LNs) on 3-year, disease-free survival was more prominent for patients with $>12 \mathrm{LNs}$ examined [37].

In general, examination of an increased number of LNs results in greater chances of identifying LN metastases, thus minimizing under-staging [14,27,32-34]. In our investigation of patients with Stage III disease, for each additional LN collected, there was 19\% increased probability of finding a positive LN. Thus, collection of six additional LNs resulted in finding one additional positive LN. In a mathematical model, the predictive probability of identifying single LN metastases was 0.25 if 12 LNs were examined and 0.46 if 18 LNs were examined [27]. Since the probability of LN positivity increases as the number examined increases, there is no minimum number that reliably stages all patients $[27,33]$. Higher LN counts, however, do not always correlate with increased rates of nodal positivity [22].

The accuracy of staging depends on multiple factors, including those that are modifiable (e.g., surgeon and pathologist) and un-modifiable (e.g., age, obesity, and socioeconomic status of the patient and anatomic location of the tumor) $[16,38,39]$. Pathologists encounter challenges in adequate LN retrieval. In Stage II colon cancer, the age of the patient, tumor size, specimen length, use of a structured pathology template, and academic status of the hospital are predictors of LN collection [40]. Up to $70 \%$ of metastases are found in LNs that are $<5 \mathrm{~mm}$ in diameter and hence likely to be missed on routine visualization or palpation [41]. Another challenge for pathologists relates to micrometastases or isolated tumor cells that are missed in routine histological examinations. Although immunohistochemistry and polymerase chain reactions to identify cytokeratin and carcinoembryonic antigen [42] have been used to highlight malignant cells, the prognostic significance of LNs containing such micro-metastases is uncertain [35]. Targeted LN examination by mapping of the most proximal LN (sentinel LN) improves the staging accuracy for colon cancer [43,44]. In LN mapping, however, there are inconsistencies [45-47] that may be attributable to inadequate standardization, training, and interpretation of micro-metastases and to skip metastases $[43,48]$.

Survival in colon cancer is influenced by the presence of positive LNs and by the total number of positive LNs [32]. For Stage III tumors, the AJCC sub-classifies nodal staging into $\mathrm{pN}_{1}$ and $\mathrm{pN}_{2}$, based on the presence of $\geq 4$ positive LNs [21]. In our analysis, the probability of having $\mathrm{pN}_{2}$ patients increased from $18 \%$ to $43 \%$ as the number of LNs examined increased from $<7$ to $\geq 20$. Similarly, there was increased disease-free survival as more LNs were examined from $\mathrm{pN}_{1}$ and $\mathrm{pN}_{2}$ patients [32]. The probability of missing a positive LN was $29.7 \%, 20.0 \%$, and $13.6 \%$ when five, eight, and twelve LNs, respectively, were examined [49]. For node-positive patients, increased numbers of LN examination correlated with a lower $\mathrm{LN}$ ratio, which was associated with a better prognosis [37,50]. Although most of these investigations involved large sample sizes, the cutoff values differed; thus, further investigations were warranted.

\section{Conclusions}

In summary, the mandatory $12 \mathrm{LNs}$ examination recommended by different agencies (AJCC, ASCO, NCCN, etc.) did not demonstrate a significantly low risk of recurrence or survival benefit. Moreover, collection of $\geq 7$ or $\geq 12$ LNs had similar outcomes. Hence, a minimum of 6 LNs should be examined for adequate staging of Stage II and III colon cancer patients. Collection of $\geq$ 20 LNs, however, was associated with reduced risk of recurrence and improved survival for Stage II but not for Stage III colon cancer patients. Also, there is an improved survival with increased numbers of LNs harvested from Stage II and Stage III patients regardless of the cutoff points used. For Stage III tumors, every six additional LNs harvested resulted in identification of a positive $\mathrm{LN}$. The probability of finding a $\mathrm{pN}_{2}$ patient increased with increasing numbers of LNs collected. Thus, to minimize stage misclassification and to aid in therapeutic decisions for colon cancer patients, the surgeons should perform more extensive lymphadenectomies and the pathologists should screen the surgical 
specimens diligently and examine as many LNs as possible. Furthermore, the findings from institutional studies, like ours, relate to the population of the serving area they represent. Thus, there may be geographic differences which can be addressed in future studies and minimized when one follows uniform treatment and pathology protocols.

\section{Financial and non-financial competing interests}

The authors declare that they have no competing interests.

\section{Acknowledgements}

This work is supported in part by grants from the National Institutes of Health/National Cancer Institute (U54-CA118948, R01-CA98932 and R03CA139629) to Dr. U. Manne. We thank Donald L. Hill, Ph.D., Division of Preventive Medicine, University of Alabama at Birmingham, for his critical review of this manuscript.

\section{Author details}

'Departments of Pathology, University of Alabama at Birmingham, Birmingham, AL 35294, USA. ${ }^{2}$ Jiann-Ping Hsu College of Public Health, Georgia Southern University, Statesboro, GA 30460, USA. ${ }^{3}$ Department of Pathology and Laboratory Medicine, University of Pennsylvania, Philadelphia, PA 19104, USA. ${ }^{4}$ Department of Biostatistics, University of Alabama at Birmingham, Birmingham, AL35294, USA. ${ }^{5}$ Department of Medicine, University of Alabama at Birmingham, Birmingham, AL35294, USA. ${ }^{6}$ Department of Surgery, Morehouse School of Medicine, Atlanta, GA 30310 USA. ${ }^{7}$ Comprehensive Cancer Center, University of Alabama at Birmingham, Birmingham, AL 35294, USA.

\section{Authors' contributions}

CKS involved in conception, design, data collection, data assembly, data analysis, data interpretation, and manuscript writing. RBH involved in conception, design, data collection, data assembly, data analysis, data interpretation, and manuscript writing. NCJ involved in conception, design, data collection, data assembly, data analysis, data interpretation, and manuscript writing. VRK involved in data collection, data assembly, data analysis, and data interpretation. BZ involved in data analysis and data interpretation. JAP involved in provision of study patients, data collection, data assembly, data analysis, data interpretation, and manuscript writing. HLB involved in data collection, data assembly, data analysis, data interpretation, and manuscript writing. WEG involved in data analysis, data interpretation, and manuscript writing. IEE involved in data analysis and data interpretation. GPS involved in data analysis, data interpretation and manuscript writing. UM involved in administrative support, conception, design, provision of study patients, data collection, data assembly, data analysis, data interpretation, and manuscript writing. All authors read and approved the final manuscript.

Received: 14 April 2011 Accepted: 28 May 2011 Published: 28 May 2011

\section{References}

1. Jemal A, Siegel R, Xu J, Ward E: Cancer statistics, 2010. CA Cancer J Clin 2010, 60:277-300.

2. Petersen VC, Baxter KJ, Love SB, Shepherd NA: Identification of objective pathological prognostic determinants and models of prognosis in Dukes' B colon cancer. Gut 2002, 51:65-69.

3. Morris EJ, Maughan NJ, Forman D, Quirke P: Who to treat with adjuvant therapy in Dukes B/stage II colorectal cancer? The need for high quality pathology. Gut 2007, 56:1419-1425.

4. Schrag D, Rifas-Shiman S, Saltz L, Bach PB, Begg CB: Adjuvant chemotherapy use for Medicare beneficiaries with stage II colon cancer. J Clin Oncol 2002, 20:3999-4005.

5. Gill S, Loprinzi CL, Sargent DJ, Thome SD, Alberts SR, Haller DG, Benedetti J, Francini G, Shepherd LE, Francois Seitz J, Labianca R, Chen W, Cha SS,
Heldebrant MP, Goldberg RM: Pooled analysis of fluorouracil-based adjuvant therapy for stage II and III colon cancer: who benefits and by how much? J Clin Oncol 2004, 22:1797-1806.

6. Glimelius B, Dahl O, Cedermark B, Jakobsen A, Bentzen SM, Starkhammar H, Gronberg H, Hultborn R, Albertsson M, Pahlman L, Tveit KM: Adjuvant chemotherapy in colorectal cancer: a joint analysis of randomised trials by the Nordic Gastrointestinal Tumour Adjuvant Therapy Group. Acta oncologica (Stockholm, Sweden) 2005, 44:904-912.

7. Andre T, Sargent D, Tabernero J, O'Connell M, Buyse M, Sobrero A, Misset $\lrcorner$, Boni $C$, de Gramont A: Current issues in adjuvant treatment of stage II colon cancer. Ann Surg Oncol 2006, 13:887-898.

8. Compton CC: Updated protocol for the examination of specimens from patients with carcinomas of the colon and rectum, excluding carcinoid tumors, lymphomas, sarcomas, and tumors of the vermiform appendix: a basis for checklists. Cancer Committee. Archives of pathology \& laboratory medicine 2000, 124:1016-1025.

9. Caplin S, Cerottini JP, Bosman FT, Constanda MT, Givel JC: For patients with Dukes' B (TNM Stage II) colorectal carcinoma, examination of six or fewer lymph nodes is related to poor prognosis. Cancer 1998, 83:666-672.

10. Steele GJ, Tepper J, Motwani B: Cancer medicine. Philadelphia: Lea \& Febiger; 31993

11. Hernanz F, Revuelta S, Redondo C, Madrazo C, Castillo J, Gomez-Fleitas M: Colorectal adenocarcinoma: quality of the assessment of lymph node metastases. Diseases of the colon and rectum 1994, 37:373-376, discussion 376-377.

12. Jestin P, Pahlman L, Glimelius B, Gunnarsson U: Cancer staging and survival in colon cancer is dependent on the quality of the pathologists' specimen examination. Eur J Cancer 2005, 41:2071-2078.

13. Park IJ, Choi GS, Jun SH: Nodal stage of stage III colon cancer: The impact of metastatic lymph node ratio. J Surg Oncol 2009.

14. Joseph NE, Sigurdson ER, Hanlon AL, Wang H, Mayer RJ, MacDonald JS, Catalano PJ, Haller DG: Accuracy of determining nodal negativity in colorectal cancer on the basis of the number of nodes retrieved on resection. Annals of surgical oncology 2003, 10:213-218.

15. Wong SL, Ji H, Hollenbeck BK, Morris AM, Baser O, Birkmeyer JD: Hospital lymph node examination rates and survival after resection for colon cancer. Jama 2007, 298:2149-2154.

16. Chang GJ, Rodriguez-Bigas MA, Skibber JM, Moyer VA: Lymph node evaluation and survival after curative resection of colon cancer: systematic review. Journal of the National Cancer Institute 2007, 99:433-441.

17. Rajput A, Romanus D, Weiser MR, ter Veer A, Niland J, Wilson J, Skibber JM, Wong YN, Benson A, Earle CC, Schrag D: Meeting the 12 lymph node (LN) benchmark in colon cancer. J Surg Oncol 2010, 102:3-9.

18. Temple LK: The prognosis of colon cancer is dependent on accurate staging. J Surg Oncol 2010, 102:1-2.

19. Fielding LP, Arsenault PA, Chapuis PH, Dent O, Gathright B, Hardcastle JD, Hermanek P, Jass JR, Newland RC: Clinicopathological staging for colorectal cancer: an International Documentation System (IDS) and an International Comprehensive Anatomical Terminology (ICAT). Journal of gastroenterology and hepatology 1991, 6:325-344.

20. Nelson H, Petrelli N, Carlin A, Couture J, Fleshman J, Guillem J, Miedema B, Ota D, Sargent D: Guidelines 2000 for colon and rectal cancer surgery. $J$ Natl Cancer Inst 2001, 93:583-596.

21. Edge SB, Byrd DR, Compton CC, Fritz AG, Greene FL, Trotti A: American Joint Committee on Cancer, American Cancer Society: AJCC Cancer Staging Manual. New York, NY: Springer-Verlag; 72010.

22. Bui $L$, Rempel $E$, Reeson D, Simunovic M: Lymph node counts, rates of positive lymph nodes, and patient survival for colon cancer surgery in Ontario, Canada: a population-based study. Journal of surgical oncology 2006, 93:439-445.

23. Chen SL, Bilchik AJ: More extensive nodal dissection improves survival for stages I to III of colon cancer: a population-based study. Annals of surgery 2006, 244:602-610

24. Law CH, Wright FC, Rapanos T, Alzahrani M, Hanna SS, Khalifa M, Smith AJ: Impact of lymph node retrieval and pathological ultra-staging on the prognosis of stage II colon cancer. Journal of surgical oncology 2003, 84:120-126.

25. Sarli L, Bader G, lusco D, Salvemini C, Mauro DD, Mazzeo A, Regina G, Roncoroni L: Number of lymph nodes examined and prognosis of TNM stage II colorectal cancer. Eur J Cancer 2005, 41:272-279. 
26. Prandi M, Lionetto R, Bini A, Francioni G, Accarpio G, Anfossi A, Ballario E, Becchi G, Bonilauri S, Carobbi A, Cavaliere P, Garcea D, Giuliani L, Morziani E, Mosca F, Mussa A, Pasqualini M, Poddie D, Tonetti F, Zardo L, Rosso R: Prognostic evaluation of stage $B$ colon cancer patients is improved by an adequate lymphadenectomy: results of a secondary analysis of a large scale adjuvant trial. Annals of surgery 2002, 235:458-463.

27. Goldstein NS: Lymph node recoveries from 2427 pT3 colorectal resection specimens spanning 45 years: recommendations for a minimum number of recovered lymph nodes based on predictive probabilities. The American journal of surgical pathology 2002, 26:179-189.

28. Kaplan E MP: Non-parametric estimation from incomplete observations. $J$ AM Stat Assoc 1958, 53.

29. Kim J, Huynh R, Abraham I, Kim E, Kumar RR: Number of lymph nodes examined and its impact on colorectal cancer staging. The American surgeon 2006, 72:902-905

30. Ricciardi R, Baxter NN: Association versus causation versus quality improvement: setting benchmarks for lymph node evaluation in colon cancer. Journal of the National Cancer Institute 2007, 99:414-415.

31. Suzuki O, Sekishita Y, Shiono T, Ono K, Fujimori M, Kondo S: Number of lymph node metastases is better predictor of prognosis than level of lymph node metastasis in patients with node-positive colon cancer. Journal of the American College of Surgeons 2006, 202:732-736.

32. Le Voyer TE, Sigurdson ER, Hanlon AL, Mayer RJ, Macdonald JS, Catalano PJ, Haller DG: Colon cancer survival is associated with increasing number of lymph nodes analyzed: a secondary survey of intergroup trial INT-0089. J Clin Oncol 2003, 21:2912-2919.

33. Ratto C, Sofo L, Ippoliti M, Merico M, Bossola M, Vecchio FM, Doglietto GB, Crucitti F: Accurate lymph-node detection in colorectal specimens resected for cancer is of prognostic significance. Diseases of the colon and rectum 1999, 42:143-154, discussion 154-148.

34. Swanson RS, Compton CC, Stewart AK, Bland KI: The prognosis of T3NO colon cancer is dependent on the number of lymph nodes examined. Annals of surgical oncology 2003, 10:65-71.

35. Cianchi F, Palomba A, Boddi V, Messerini L, Pucciani F, Perigli G, Bechi P, Cortesini C: Lymph node recovery from colorectal tumor specimens: recommendation for a minimum number of lymph nodes to be examined. World J Surg 2002, 26:384-389.

36. Tsikitis VL, Larson DL, Wolff BG, Kennedy G, Diehl N, Qin R, Dozois EJ, Cima RR: Survival in stage III colon cancer is independent of the total number of lymph nodes retrieved. J Am Coll Surg 2009, 208:42-47.

37. Park IJ, Choi GS, Jun SH: Nodal stage of stage III colon cancer: the impact of metastatic lymph node ratio. Journal of surgical oncology 2009, 100:240-243.

38. McBride RB, Lebwohl B, Hershman DL, Neugut Al: Impact of socioeconomic status on extent of lymph node dissection for colon cancer. Cancer Epidemiol Biomarkers Prev 2010, 19:738-745.

39. Nash GM, Row D, Weiss A, Shia J, Guillem JG, Paty PB, Gonen M, Weiser MR, Temple LK, Fitzmaurice G, Wong WD: A Predictive Model for Lymph Node Yield in Colon Cancer Resection Specimens. Ann Surg 2010.

40. Wright FC, Law CH, Last L, Khalifa M, Arnaout A, Naseer Z, Klar N, Gallinger S, Smith AJ: Lymph node retrieval and assessment in stage II colorectal cancer: a population-based study. Annals of surgical oncology 2003, 10:903-909.

41. Rodriguez-Bigas MA, Maamoun S, Weber TK, Penetrante RB, Blumenson LE, Petrelli NJ: Clinical significance of colorectal cancer: metastases in lymph nodes < 5 mm in size. Annals of surgical oncology 1996, 3:124-130.

42. Rosenberg R, Hoos A, Mueller J, Baier P, Stricker D, Werner M, Nekarda H, Siewert JR: Prognostic significance of cytokeratin-20 reverse transcriptase polymerase chain reaction in lymph nodes of node-negative colorectal cancer patients. J Clin Oncol 2002, 20:1049-1055.

43. Bilchik AJ, Wood TF, Allegra D, Tsioulias GJ, Chung M, Rose DM, Ramming KP, Morton DL: Cryosurgical ablation and radiofrequency ablation for unresectable hepatic malignant neoplasms: a proposed algorithm. Arch Surg 2000, 135:657-662, discussion 662-654.

44. Tsioulias GJ, Wood TF, Morton DL, Bilchik AJ: Lymphatic mapping and focused analysis of sentinel lymph nodes upstage gastrointestinal neoplasms. Arch Surg 2000, 135:926-932.

45. Saha S, Nora D, Wong JH, Weise D: Sentinel lymph node mapping in colorectal cancer-a review. The Surgical clinics of North America 2000, 80:1811-1819.
46. Bendavid Y, Latulippe JF, Younan RJ, Leclerc YE, Dube S, Heyen F, Morin M, Girard R, Bastien E, Ferreira J, Cerino M, Dube P: Phase I study on sentinel lymph node mapping in colon cancer: a preliminary report. J Surg Oncol 2002, 79:81-84, discussion 85.

47. Paramo JC, Summerall J, Poppiti R, Mesko TW: Validation of sentinel node mapping in patients with colon cancer. Ann Surg Oncol 2002, 9:550-554.

48. Kelder W, van den Berg A, van der Leij J, Bleeker W, Tiebosch AT, Grond JK, Baas PC, Plukker JT: RT-PCR and immunohistochemical evaluation of sentinel lymph nodes after in vivo mapping with Patent Blue $\mathrm{V}$ in colon cancer patients. Scandinavian journal of gastroenterology 2006, 41:1073-1078.

49. Gonen M, Schrag D, Weiser MR: Nodal staging score: a tool to assess adequate staging of node-negative colon cancer. J Clin Oncol 2009, 27:6166-6171

50. Engstrom PF, Benson AB, Chen YJ, Choti MA, Dilawari RA, Enke CA, Fakih MG, Fuchs C, Kiel K, Knol JA, Leong LA, Ludwig KA, Martin EW Jr, Rao S, Saif MW, Saltz L, Skibber JM, Venook AP, Yeatman TJ: Colon cancer clinical practice guidelines in oncology. J Natl Compr Canc Netw 2005, 3:468-491.

doi:10.1186/1756-8722-4-25

Cite this article as: Shanmugam et al:: Evaluation of lymph node numbers for adequate staging of Stage II and III colon cancer. Journal of Hematology \& Oncology 2011 4:25.

\section{Submit your next manuscript to BioMed Central and take full advantage of:}

- Convenient online submission

- Thorough peer review

- No space constraints or color figure charges

- Immediate publication on acceptance

- Inclusion in PubMed, CAS, Scopus and Google Scholar

- Research which is freely available for redistribution

Submit your manuscript at www.biomedcentral.com/submit
C) Biomed Central 